\title{
ЭЛЕКТРИЧЕСКОЕ ПОЛЕ НА ПОВЕРХНОСТИ ПРОВОДЯЩЕЙ ПОЛЯРИЗУЮЩЕЙСЯ СРЕДЫ ПРИ ИСПОЛЬЗОВАНИИ СИММЕТРИЧНЫХ И ЭКВАТОРИАЛЬНЫХ УСТАНОВОК
}

\author{
Е. В. Агеенков ${ }^{1}$, А. А. Ситников ${ }^{2}$, И. Ю. Пестерев ${ }^{2}$, В. В. Владимиров ${ }^{2}$ \\ ${ }^{1}$ Иркутский национальный исследовательский технический университет \\ ${ }^{2}$ ООО «Сибирская геофизическая научно-производственная компания», г. Иркутск
}

Поступила в редакцию 27 декабря 2018 г.

\begin{abstract}
Аннотация: научная задача публикации исследовать переходный процесс электрического поля на поверхности проводящей поляризующейся Земли, для экваториальной области источника - электрическая линия. Использовать для этого ряд одномерных моделей, в которых вызванная поляризачия (ВП) возникает в верхней и нижней части геологических образований, разделённых высокоомным экраном. Показать отличие проявления ЭМ сигнала, связанного с поляризацией, вызванной гальваническим (ВПГ) и вихревым током (ВПИ), в измерениях сигнала переходного проиесса на измерительных линиях. Исследование основано на результатах решения прямой задачи импульсной электроразведки с электрическими линиями, в которой ВП учитывается введением частотно зависимого удельного электрического сопротивления формулой Коула-Коула, и построении зависимости сигнала переходного проиесса $(\Delta U(t))$.
\end{abstract}

Ключевые слова: индукционно вызванная поляризаџия (ВПИ), гальванически вызванная поляризаичия (ВПГ), заземлённая электрическая линия, экваториальная область источника.

\section{ELECTRICAL FIELD ON THE SURFACE OF CONDACTIVE POLARIZABLE MEDIEM ON VENNER AND EQUATORIAL ARRAYS}

\begin{abstract}
: the scientific aim of the paper is electrical field transient research above conductive polarizable Earth for the equatorial areas of the source - electrical line. To use for this purpose a number of onedimensional models in which the IP is created on the upper and down section parts which separated by high resistive screen. To show the difference in the signal of the transient process on measuring lines, with galvanic and inductive excitation of the induced polarization predominating for visual allocation of the time range when in general the signal of the transient process is dominated by the formation signal, galvanically induced polarization (IPG), and induction-induced polarization (IPI). The study is based on the results of solving a direct problem of pulsed electrical reconnaissance with earthed lines, in which the IP is taken into account by introducing the frequency-dependent resistivity by the Cole-Cole formula and transient $(\Delta U(t))$ visualization.
\end{abstract}

Key words: induction induce polarization (IPI), galvanically induce polarization (IPG), grounded electrical line, equatorial areas of the electrical line.

\section{Введение}

Процесс вызванной поляризации возникает в многофазной гетерогенной геологической среде после протекания в ней внешнего тока [1], нарушающего её равновесное состояние, и релаксации в первоначальное состояние после прекращения этого воздействия. Во время релаксации процесс ВП проявляется как ЭМ сигнал [2] и может быть зарегистрирован измерителями ЭМ поля над средой, на её поверхности или внутри неё.

Искусственные источники ЭМ поля, такие как индуктивная петля [3], заземлённая на поверхности или внутри проводящей поляризующейся Земли электрическая линия [3] или круговой электрический диполь [4] по-разному воздействуют на среду, создавая в ней различные структуры токов и полей. В нашей публикации ограничимся исследованием воздействия горизонтальной электрической линии, заземлённой на поверхности проводящей поляризующейся одномерной Земли.

Горизонтальная индуктивная петля создаёт в среде вихревые токи, текущие в ней преимущественно горизонтально. В импульсном режиме диффузия вихревого тока вглубь геологической среды вызывает её 
поляризацию, которая при релаксации порождает токи вызванной поляризации индукционной природы. Эти явления (диффузия тока и поляризация) образуют ЭМ сигнал - становления ЭМ поля и ВПИ, регистрируемый измерителями.

Круговой электрический диполь в одномерной среде создаёт тороидальную систему токов, подавляющую индуктивную составляющую ЭМ поля, и образующую, таким образом, только поле электрического типа, под воздействием которого в проводящей среде текут гальванические токи. В реальной геологической среде, отличающейся от идеальной одномерной модели, такой источник будет возбуждать аномальное магнитное поле и аномальный вихревой ток, связанные с нарушениями латеральной однородности ЭМ свойств среды.

Горизонтальная электрическая линия в импульсном режиме создаёт в среде гальванические токи в момент импульса и вихревые токи в момент выключения и включения (изменения) тока, текущего в проводе и в Земле. Гальванический и вихревой токи вызывают в Земле поляризацию и процесс становления ЭМ поля, которые сопровождаются ЭМ сигналом гальванически и индукционно вызванной поляризации и становления.

\section{Электрические установки для изучения ВП}

Заземлённая электрическая линия состоит из отрезка проводника (провода, кабеля) и двух гальванических контактов с геологической средой, осуществляемых электродами А и В. Генераторная установка подключается к линии и во время импульса тока на одном из них создаёт положительный потенциал, на другом отрицательный. Проводящая Земля замыкает цепь. Между электродами А и В по проводу ток течёт в одну сторону, в Земле в другую. Так вокруг горизонтальной электрической линии создаются области, где гальванический ток течёт в разном направлении относительно заземлений, которыми линия контактирует со средой - это осевая и экваториальная области источника.

Гальванически заземлённая линия в импульсном режиме пропускания тока в проводящей Земле возбуждает индуктивный переходный процесс, ВПГ и ВПИ [5]. Во время токового импульса в поляризующейся среде протекают процессы разделения зарядов различной природы. Главным образом, это электрокинетические явления, возникающие на границе жидкой фазы и ионных проводников - мембранная поляризация, поляризация, связанная с диффузионным потенциалом, и электрохимические явления, протекающие на границе жидкой фазы и электронных проводников (рудных включений) - электролитическая поляризация.

После прекращения этого воздействия начинаются обратные релаксационные процессы, проявляющиеся как ЭМ сигнал, регистрируемый измерителем совместно с ЭМ сигналом, связанным с диффузией вихревых токов внутрь проводящей Земли. Вихре- вые токи, распространяющиеся внутри поляризующейся среды (рис. 1а), также индуцируют процессы разделения зарядов, которые после их ослабления, а затем и затухания становятся обратными релаксационными процессами, также проявляющиеся как дополнительный ЭМ сигнал, регистрируемый измерителем. Это описание последствий импульсного воздействия заземлённой электрической линии на проводящую поляризующуюся Землю показывает, что оно сложнее, чем при таком же воздействии индуктивного источника. Однако именно заземлённая линия чаще используется для изучения ВП, т.к. плотность гальванических токов, «заряжающих» Землю, выше, чем у вихревых токов незаземлённого источника, а время воздействия определяется продолжительностью токового импульса, а не продолжительностью переходного процесса, как для индуктивного источника.
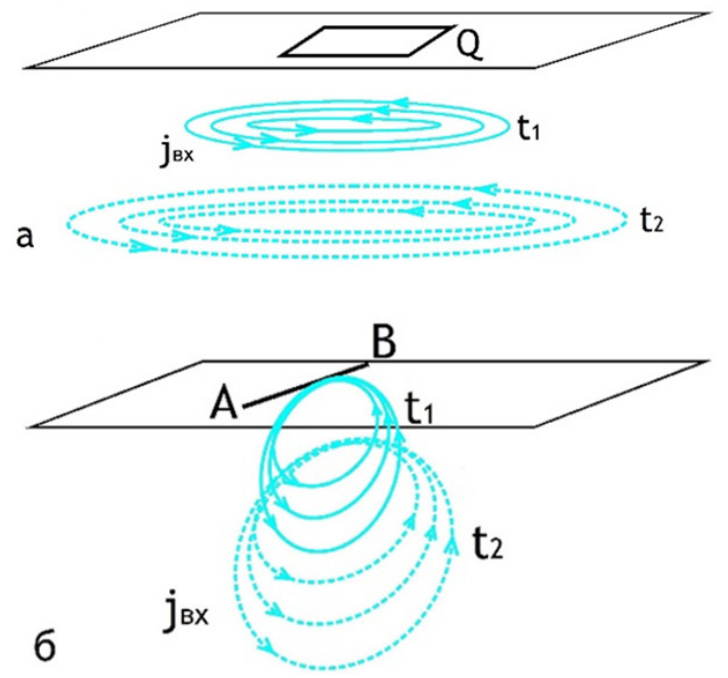

Puc. 1. Схема перемещения максимума плотности вихревых токов во время переходного процесса: а) для источника индуктивная петля; б) заземлённая линия.

В основе исследования лежат результаты решения прямой задачи горизонтальной электрической компоненты неустановившегося ЭМ поля для одномерной проводящей поляризующейся Земли. ВП среды учитывается частотно зависимым удельным электрическим сопротивлением (УЭС) по формуле Коула-Коула (1):

$$
\rho(\omega)=\rho_{0}\left(1-\frac{\eta(i \omega \tau)^{c}}{1+(i \omega \tau)^{c}}\right),
$$

где $\rho_{0}-$ УЭС на постоянном токе (Ом·м); $\eta-$ коэффициент поляризуемости (доли ед.); $\tau$ - постоянная времени (c); $c$ - показатель степени; $\omega$ - круговая частота $\left(\right.$ сек $\left.^{-1}\right)$.

Использовался метод линейной фильтрации решения задачи ЭМ становления [6]. Он основан на первоначальном получении частотной характеристики сигнала в широком диапазоне частот, затем путём преобразования Фурье решения во временной области. 


\section{Переходный процесс над проводящей поляризующейся Землёй для симметричной электрической установки}

Проявление сигнала ВП после импульсного воздействия для электрических линий в осевой [7] и экваториальной $[6,8,9]$ области источника исследовались неоднократно, однако, не проводилось разделение - какой вид тока порождает релаксационные процессы, гальванический или вихревой или той и другой природы.

Проявление сигнала ВПИ изучалось для индуктивной установки $[2,10,11,12]$, для заземлённых электрических линий этот вопрос исследовался меньше [6, 7, 13]. Легейдо [13] предложил ряд геоэлектрических моделей, основанных на геологических условиях Юга Сибирской платформы (табл. 1), в которых поляризующимися являются два слоя, разделённые высокоомным экраном: первый и третий. В первом приближении ВП таких моделей связано преимущественно с гальваническим током («ВПГ») - при поляризующемся первом слое, преимущественно с вихревым током («ВПИ») - при поляризующемся слое под экраном, с двумя типами тока («ВПГ и ВПИ») - при поляризующихся и первом и третьем слоях и модель, в которой ВП не образуется («Без ВП»).

Геоэлектрические модели численных расчётов

\begin{tabular}{|c|c|c|c|c|c|c|c|c|}
\hline \multirow{2}{*}{ Слой } & \multirow{2}{*}{$\rho, \mathrm{OM}^{\prime} \cdot \mathbf{M}$} & \multicolumn{4}{|c|}{$\eta, \%$} & \multirow{2}{*}{$\tau, \mathrm{c}$} & \multirow{2}{*}{ c, б.p. } & \multirow{2}{*}{ h, $\mathrm{m}$} \\
\hline & & Без ВП & ВПГ & ВПГ и ВПИ & ВПИ & & & \\
\hline 1 & 50 & 0 & 2 & 2 & 0 & 0,5 & 0,5 & 200 \\
\hline 2 & 1000 & 0 & 0 & 0 & 0 & & & 500 \\
\hline 3 & 20 & 0 & 0 & 50 & 50 & 0,5 & 0,5 & 200 \\
\hline 4 & 1000 & 0 & 0 & 0 & 0 & & & \\
\hline
\end{tabular}

Расчёты сделаны для симметричных установок с разной длиной источника и измерителя. А 75 M $50 \mathrm{~N}$ 75 В (длина источника 200 м, измерителя - 50 м), А 200 M 200 N 200 В (длина источника 600 м, измерителя - 200 м), А 300 М 400 N 300 В (длина источника 1000 м, измерителя - 400 м), А 1500 М 1000 N 1500 В (длина источника 4000 м, измерителя -1000 м).

Для установки с длиной источника 200 м, эффективная глубина проникновения постоянного тока составляет от 50 до 20 м, в зависимости от проводимости разреза. В нашем случае геологическая среда задана высокоомной, и глубинность будет больше, около 50 м, однако, она не превысит мощности первого слоя - 200 м. Т.к. сигналы от моделей «ВПГ» и «ВПГ и ВПИ» практически совпадают (рис. 2а), можно предположить, что ВП, связанная с гальваническим током, будет преобладать в общем сигнале. В отсутствии поляризации верхней части среды (модель «ВПИ»), индукционно вызванная поляризация, связанная с поляризуемостью нижнего горизонта, начинает проявляться со времени 10 мс (начинается отклонение от сигнала неполяризующейся модели), а на времени порядка 30 мс происходит смена знака сигнала переходного процесса.

Для установки с длиной источника 600 м, эффективная глубина проникновения постоянного тока составляет от 150 до 60 м, в зависимости от проводимости разреза. В нашем случае глубинность будет около 150 м и она не превысит мощности первого слоя - 200 м. Как и для предыдущей установки, сигналы от моделей «ВПГ» и «ВПГ и ВПИ» практически совпадают и вновь ВП, связанная с гальваническим током, будет преобладать в общем сигнале (рис. 2б). В отсутствии поляризации верхней части среды (модель «ВПИ»), индукционно вызванная поляризация, связанная с поляризуемостью нижнего горизонта, начинает про- являться со времени 10 мс (начинается отклонение от сигнала неполяризующейся модели), смена знака сигнала переходного процесса происходит на времени порядка 30 мс. Аналогичное поведение сигнала ВПИ наблюдается и для описанной выше установки.

Для установки с длиной источника 1000 м, эффективная глубина проникновения постоянного тока составляет от 250 до 100 м, в зависимости от проводимости разреза. В нашем случае высокоомной среды глубинность будет больше, около 250 м, она превысит мощность первого слоя - 200 м. Для такой установки сигнал от модели «ВПГ и ВПИ» незначительно преобладает над сигналом от модели «ВПГ», что можно объяснить гальваническим возбуждением первого и третьего слоёв, заметно небольшое различие во времени смены знака сигнала (7,3 и 8,5 мс) для этих откликов (рис. 2в). Поведение сигнала от модели «ВПИ» аналогично такому же сигналу для установок с АВ 200 и 600 м. Сигнал ВПИ нижнего горизонта, начинает проявляться со времени 10 мс (начинается отклонение от сигнала неполяризующейся модели), смена знака сигнала переходного процесса происходит так же на времени порядка 30 мс.

Для установки с длиной источника 4000 м, эффективная глубина проникновения постоянного тока составляет от 1000 до 400 м, в нашем случае геологическая среда задана высокоомной и глубинность будет больше, около 1000 м и постоянный ток будет проникать ниже высокоомного горизонта, подошва которого расположена на глубине 700 м. Сигнал, условно названный «ВПИ», будет вызван гальваническим током, т.к. он будет проникать под высокоомную толщу и возбуждать сильно поляризующийся горизонт (с поляризуемостью 50\%) (рис. 2г). Общий сигнал будет складываться из гальванически вызванной поляризации от первого и третьего слоёв. Сигнал от модели 


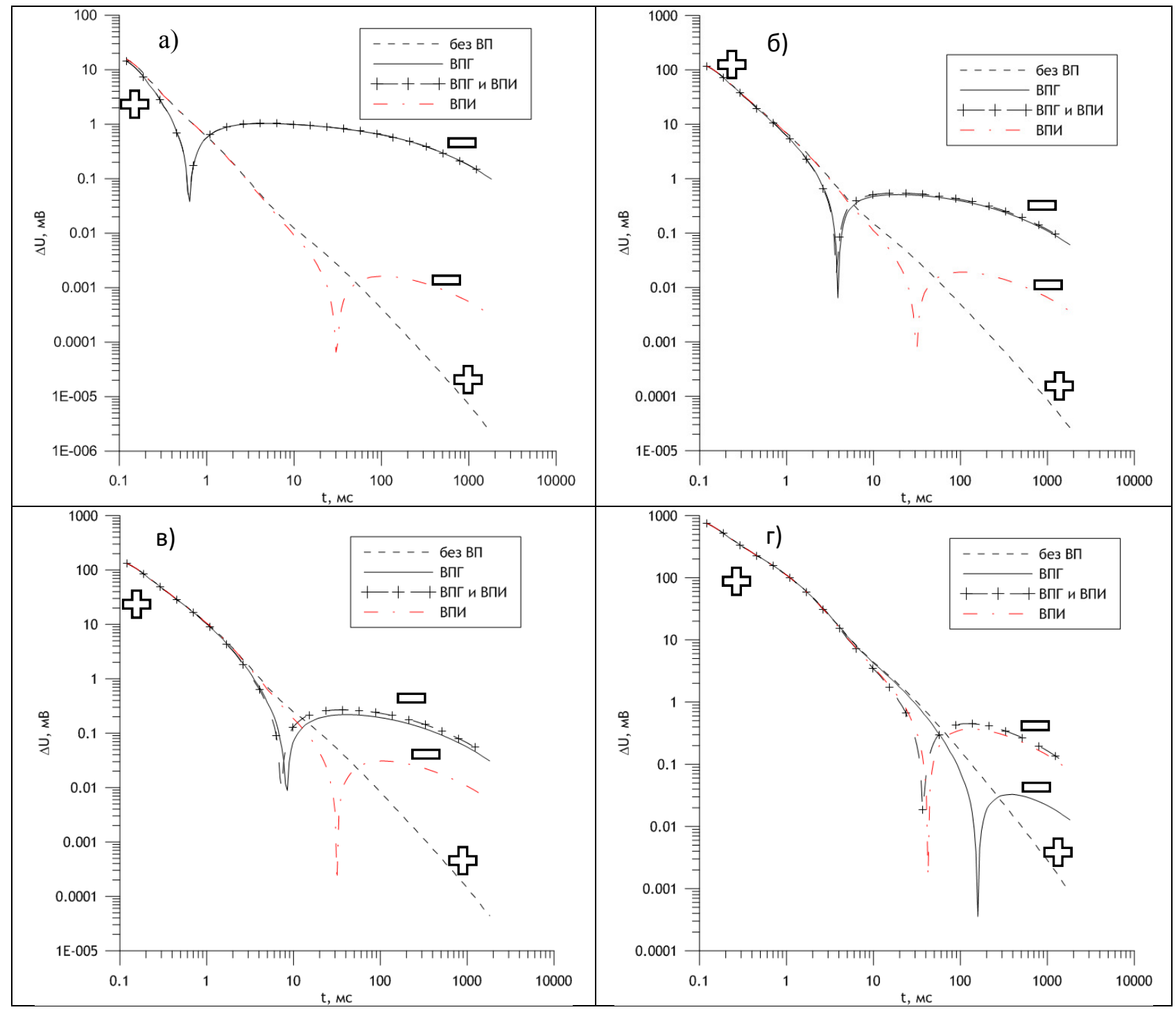

Puc. 2. а) Длина источника - 200 м. Сигнал ВПГ совпадает с общим сигналом. Отклик ВПИ значительно слабее, чем отклик ВПГ; б) Длина источника - 600 м. Сигнал ВПГ очень близок к общему сигналу. Отклик ВПИ значительно слабее, чем отклик ВПГ; в) Длина источника - 1000 м. Сигнал ВПГ по амплитуде близок к общему сигналу, однако есть различие во времени смены знака сигнала. Отклик ВПИ слабее, чем отклик ВПГ; г) Длина источника - 4000 м. Сигнал ВПИ близок к общему сигналу. Отклик ВПГ слабее, чем отклик ВПИ. Знаками «+» и «-» показаны области положительных и отрицательных значений поля переходного процесса.

«ВПГ», вызванный поляризуемостью первого слоя, значительно слабее сигнала от моделей «ВПИ» и «ВПГ и ВПИ», что можно объяснить меньшими значениями поляризуемости этого слоя $(2 \%)$ и меньшей плотностью гальванического тока, текущего в этом слое, т.к. при такой длине источника он растекается до глубины 1000 м. Можно отметить увеличение времени смены знака переходного процесса для сигнала от модели «ВПИ» он незначительно увеличивается до 42 мс. Для сигнала от модели «ВПГ» смена знака происходит на времени 158 мс, что значительно больше, чем для установки с длиной источника 200 м - 0,63 мс, для установки с источником 600 м3,88 мс и для установки с АВ 1000 м - 8,5 мс.

\section{Переходный процесс над проводящей поляризующейся Землёй для} экваториальной электрической установки

Для экваториальных установок, с измерителем, расположенным параллельно источнику, расчёты проводились для таких же четырёх моделей. Измеритель удалён от источника на длину равную длине источника для получения глубинности сопоставимой с глубинностью симметричной установки с такой же длиной источника (рис. 3).

Для установки с источником длиной 200 м и измерительной линией, расположенной параллельно источнику, на удалении 200 м, переходный процесс схож с переходным процессом, регистрируемым симметричной установкой (рис. 4a). Время смены знака сигнала для моделей «ВПГ» и «ВПГ и ВПИ» - 2,3 мс 
(для симметричной установки $-0,6$ мс), для модели «ВПИ» - 31 мс (для симметричной установки аналогичное время).

Для установки с источником длиной 600 м и измерительной линией, расположенной параллельно источнику на удалении 600 м, переходный процесс значительно сложнее, чем для симметричной установки с такой же длиной источника (рис. 4б). На ранних временах сигнал переходного процесса противоположного знака относительно знака сигнала импульса, затем происходит смена знака сигнала на времени 0,55 мс, а позднее для поляризующихся моделей «ВПГ», «ВПГ и ВПИ» и «ВПИ» сигнал вновь меняет свой знак. Время смены знака от модели «ВПИ» - 31 мс, как и для симметричной установки.

Для установки с источником длиной 1000 м и измерительной линией, расположенной параллельно источнику на удалении 1000 м, переходный процесс так же сложнее чем для симметричной установки с такой же длиной источника (рис. 4в). На ранних временах сигнал переходного процесса противоположного знака относительно знака сигнала импульса, затем происходит смена знака сигнала на времени 1,2 мс,

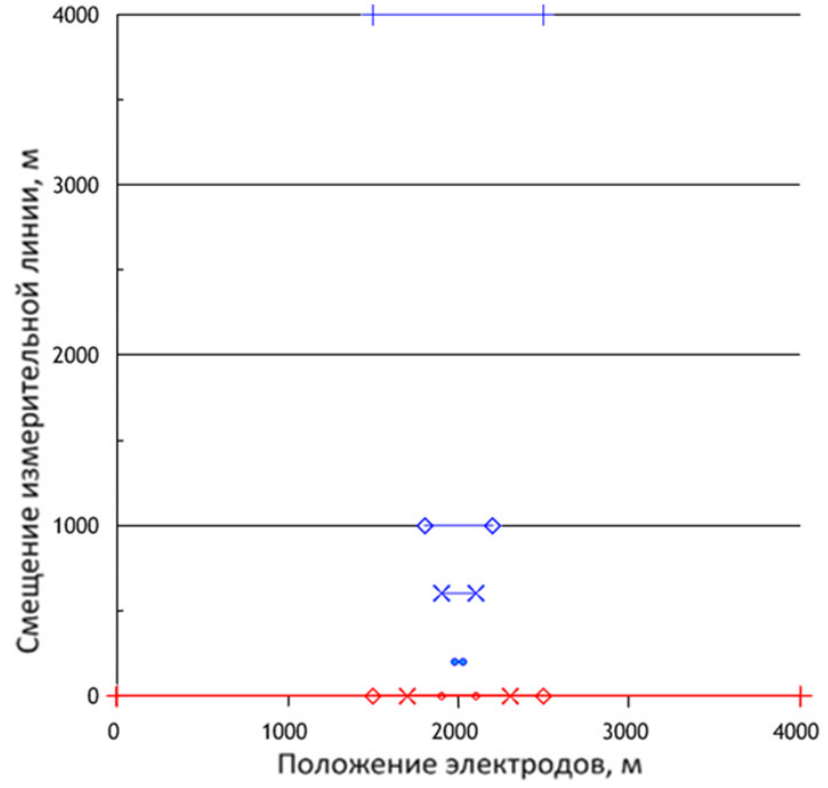

Puc. 3. Схема экваториальных установок, для которых проводились расчёты. Источники показаны красными линиями, измерители - синими.

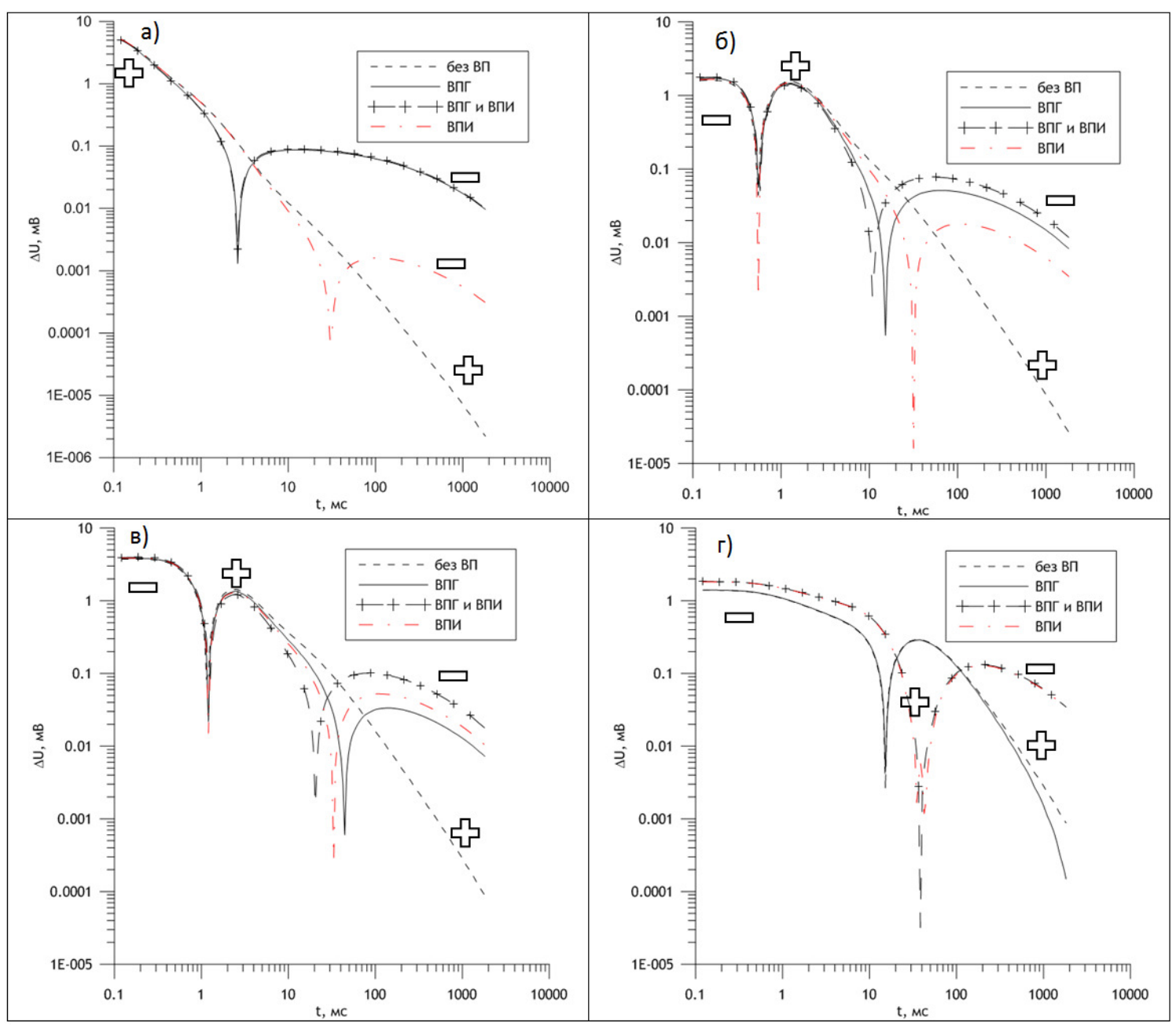

Puc. 4. а) Длина источника - 200 м, приёмник находится на расстоянии 200 м от центра источника на его экваторе. Сигнал ВПГ совпадает с общим сигналом. Отклик ВПИ значительно слабее, чем отклик ВПГ; б) Длина источника - 600 м, при- 
ёмник находится на расстоянии 600 м от центра источника на его экваторе. Общий сигнал «ВПГ и ВПИ» больше, чем сигналы «ВПГ» и «ВПИ». Отклик «ВПИ» слабее, чем отклик «ВПГ»; в) Длина источника - 1000 м, приёмник находится на расстоянии 1000 м от центра источника на его экваторе. Общий сигнал «ВПГ и ВПИ» больше сигналов «ВПИ» и «ВПГ». Сигнал «ВПИ» преобладает над сигналом «ВПГ»; г) Длина источника - 4000 м, приёмник находится на расстоянии 4000 м от центра источника на его экваторе. При таком разносе проявление поляризационного сигнала от модели «ВПГ» и от моделей «ВПИ и ВПГ» и «ВПИ» значительно различается. Знаками «+» и «-» показаны области положительных и отрицательных значений поля переходного процесса.

а позднее для поляризующихся моделей «ВПГ», «ВПГ и ВПИ» и «ВПИ» сигнал вновь меняет свой знак. Время смены знака от модели «ВПИ» увеличивается до 33 мс (для симметричной установки - 31 мс).

Для установки с источником длиной 4000 м и измерительной линией, расположенной параллельно источнику на удалении 4000 м, переходный процесс так же сложнее, чем для симметричной установки с такой же длиной источника (рис. 4г).

На ранних временах сигнал переходного процесса противоположного знака относительно знака сигнала импульса, затем на времени 15,2 мс для сигнала от моделей «без ВП» и «ВПГ» происходит смена знака сигнала. Для модели «без ВП» сигнал больше не меняет знак. Для модели «ВПГ», на временном интервале расчёта сигнала, ещё одной смены знака не происходит, наблюдается лишь отклонение от сигнала от модели «без ВП», на поздних временах позднее 450 мс. Для такой динамики изменения сигнала переходного процесса можно предположить смену его знака позднее 2000 мс. Для моделей «ВПГ и ВПИ» и «ВПИ» сигнал на непродолжительное время меняет свой знак, становится таким же, как сигнал питающего импульса (с 34,9 до 42,4 мс для модели «ВПИ» и только на коротком временном диапазоне, около 38,5 мс, сигнал становится положительным для модели «ВПГ и ВПИ»), а затем сигнал приобретает знак противоположный знаку импульса и таким остаётся до окончания переходного процесса.

\section{Выводы}

Вклад гальванически вызванной поляризации в общий сигнал переходного процесса для симметричных установок оказывается значительнее, чем вклад индукционно вызванной поляризации. Пока гальванический ток из-за увеличения источника до 4000 м не начинает проникать под высокоомный экран, где располагается очень поляризующийся объект, влияние этого объекта на переходный процесс слабо и маскируется под поляризационным откликом верхней части среды, где располагается слабо поляризующийся слой.

Для экваториальных установок (при параллельном расположении питающей и измерительной линии) поведение переходного процесса над моделью «ВПИ» можно объяснить так. Когда сигнал ВП связан с вихревым током, то геометрия установки не играет существенной роли, а определяется проводящими и поляризационными свойствами среды, поэтому время смены знака сигнала для симметричной и параллельной установки при $\mathrm{AB}=200,600$ м оста- ётся неизменным - 31 мс. Как только ВП нижнего поляризующегося горизонта инициируется и вихревым и гальваническим током (при $\mathrm{AB}=1000$ и 4000 м) время изменения знака сигнала изменяется (увеличивается) и оно становится зависимым от геометрии установки.

Для параллельных установок при увеличении расстояния от источника увеличивается продолжительность времени проявления сигнала характерного для волновой зоны источника (начиная с ранних времён), когда первичное поле распространяется по верхнему непроводящему полупространству, и переходный процесс имеет противоположный знак возбуждающему импульсу. Затем происходит смена знака, свидетельствующая о начале переходного процесса, вызванного вихревым полем, распространившимся внутри геологической среды. Следующая смена знака сигнала свидетельствует о проявлении процесса вызванной поляризации.

\section{Заключение}

Изменения сигнал на измерительных линиях над проводящей поляризующейся Землёй зависят от длины заземленного источника. Анализ графиков для разных симметричных установок показывает пока гальванический ток не проник под высокоомный экран и не возбудил сильно поляризующийся слой заметных изменений графики не претерпели. Подавляющий вклад в сигнал от поляризующейся среды вносит гальванически вызванная поляризация. Сигнал вызванной поляризации связанный как с гальваническим, так и вихревым током проявляется в сигнале переходного процесса сменой знака относительно сигнала становления поля.

На экваториальных установках на ранних временах проявляется сигнал, вызванный первичным полем волнового характера, распространяющимся по воздуху. Для такого сигнала характерна обратная полярность относительно знака возбуждающего импульса. Позднее наблюдается индуктивный переходный процесс и проявление ВП.

Проведённые расчёты показывают различный характер протекания процессов становления и вызванной поляризации для симметричных и экваториальных электрических установок. Это говорит о возможности изучения характеристик как одного, так и другого процесса. Сигнал переходного процесса на симметричных установках проще, чем на экваториальных, поэтому, на наш взгляд, такие установки более практичны для проведения интерпретации измеренного сигнала. 


\section{ЛИТЕРАТУРА}

1. Шейнманн, М. С. Современные физические основы теории электроразведки / М. С. Шейнманн. - М. : Недра, 1969. $-224 \mathrm{c}$.

2. Каменецкий, Ф. М. Три лекции о вызванной поляризации геологической среды / Ф. М. Каменецкий, Г. М. Тригубович, А. В. Чернышёв. - Мюнхен: Вела Ферлаг, 2014. - 58 с. 3. Матвеев, Б. К. Электроразведка / Б. К. Матвеев. - М. : Недра, 1990. - 368 с.

4. Могилатов, В. С. Импульсная электроразведка / В. С. Могилатов. - Новосибирск : НГУ, 2014. - 300 с.

5. Агеенков, E. В. Проявление разных типов вызванной поляризации в электромагнитных измерениях заземлённой линией / Е. В. Агеенков, А. А. Ситников, И. Ю. Пестерев // Геофизика. - 2018. - № 2. - С. 37-43.

6. Петров, A. A. Возможности метода становления электрического поля при поисках углеводородов в шельфовых зонах / А. А. Петров // Геофизика. - 2000. - № 5. - С. 21-26.

7. Моисеев, В. С. Метод вызванной поляризации при поисках нефтеперспективных площадей / В. С. Моисеев. - Новосибирск : Наука, 2002. - 135 с.

8. Комаров, В. А. Электроразведка методом вызванной поляризации / В. А. Комаров. - Л.: Недра, 1980. - 391 с.

9. Вишняков, А. Э. Влияние временных параметров вызван- ной поляризации залежей углеводородов на переходные процессы электромагнитного поля / А. Э. Вишняков, Е. Д. Лисицын, М. Ю. Яневич // Техника и методика геофизических и исследований Мирового океана. Сборник научных трудов - 1988. - С. 124-132.

10. Компаниеи, С. В. Проявление и учёт индукционновызванной поляризации при изучении осадочного чехла юга сибирской платформы методом ЗСБ / С. В. Компаниец, Н. О. Кожевников, Е. Ю. Антонов // Геофизика. - 2013. - № 1. - C. 35-40.

11. Кожевников, Н. О. Быстропротекающая индукционновызванная поляризация в мёрзлых породах / Н. О. Кожевников // Геология и геофизика. - 2012. - № 4 (Т. 53). - С. 527 540.

12. Халлбауэр-Задорожная, В. Ю. Процессы, происходящие в горных породах при наложении электрического тока и разности потенциалов: вызванная поляризация / В. Ю. Халлбауэр-Задорожная // Вопросы естествознания. - 2016. № 3(11). - С. 76-79.

13. Легейдо, П. Ю. Теория и технология дифференциальнонормированной геоэлектроразведки для изучения поляризующихся разрезов в нефтегазовой геофизике / П. Ю. Легейдо. - Дис. на соиск. уч. ст. д. г.-м. н. - Иркутск : ИрГТУ, 1998. - $198 \mathrm{c}$.
ФГБОУ ВО «Иркутский национальный исследовательский технический университет»

Агеенков Евгений Валерьевич, дочент кафедры геологии, геофизики и геоинформационных систем E-mail:aev@dnme.ru; Тел.: +7 (3952) 405405

ООО «Сибирская геофизическая научно-производственная компания», г. Иркутск

Ситников Александр Анатольевич, генеральный директор E-mail:aas@dnme.ru

Тел.: +7 (3952) $383701,+7$ (3952) 436044

Пестрев Иван Юрьевич, ведущуий геофизик E-mail: ip@dnme.ru

Тел.: +7 (3952) 3837 01, +7 (3952) 436044

Владимиров Виктор Валерьевич, ведущчий геофизик

E-mail:vvv@dnme.ru

Тел.: +7 (3952) $383701,+7$ (3952) 436044
Irkutsk National Research Technical University

Ageenkov E. V., associate Professor Department of Geology,

Geophysics and Geoinformation Systems

E-mail:aev@dnme.ru

Tel.: +7 (3952) 405405

Siberian Geophysical Research Production Company Ltd, Irkutsk

Sitnikov A. A., the Director-General

E-mail:aas@dnme.ru

Tel.: +7 (3952) 3837 01, +7 (395-2) 436044

Pesterev I. Y., senior geophysicist

E-mail:ip@dnme.ru

Tel.: +7 (3952) $383701,+7$ (3952) 436044

Vladimirov V. V., senior geophysicis

E-mail:vvv@dnme.ru

Tel.: +7 (3952) 3837 01, +7 (3952) 436044 